Check for updates

University of Oxford

triya.chakravorty@queens.ox.acukTwitter @triyaac

Cite this as: $B M J 2021 ; 375: \mathrm{n} 2830$ http://dx.doi.org/10.1136/bmi.n2830 Published: 17 November 2021

\section{Fat shaming is stopping doctors from helping overweight patients-here's what medical students can do about it}

\section{Obesity stigma can harm people's health and is even more damaging when it comes from healthcare professionals, says Triya Chakravorty}

Triya Chakravorty sixth year medical student

People who are obese are highly stigmatised in society and face many forms of discrimination due to their weight. ${ }^{1}$ This weight bias translates into inequalities faced in healthcare, employment, and education. ${ }^{1}$ In a healthcare setting, negative attitudes held by healthcare professionals will make patients feel stigmatised and reluctant to access healthcare services, further damaging their long term health. The social stigma faced by overweight healthcare professionals will also have an impact on their own confidence and ability to deliver healthcare advice. ${ }^{2}$

\section{The healthcare harms}

Although obesity is a risk factor for several diseases and many public health interventions rightly aim to reduce it, ${ }^{3}$ the stigma around obesity does not make obese people healthier. Instead, it increases individuals' risk of depression and suicide, and further entrenches disordered eating behaviours. ${ }^{14}$ Such negative perceptions also make people less likely to engage with preventative healthcare services. ${ }^{5}$ In other words, fat shaming does not work as a weight loss tool ${ }^{6}$ and can even harm health.

This stigma has perhaps the most damaging effect when it comes from healthcare providers themselves. Research has found that healthcare professionals often believe that overweight patients are less compliant with advice about weight loss. ${ }^{1}$ In a study of 2500 overweight individuals in the US, Puhl and Brownwell found that $53 \%$ reported receiving inappropriate comments from doctors about their weight. ${ }^{6}$ These negative interactions with healthcare professionals can deter patients from accessing medical care due to fears of being judged. Several studies have shown that obese individuals are less likely to take part in screening programmes for breast, cervical, and colorectal cancer. ${ }^{17}$

Obesity stigma may also increase the risk of eating disorders. A growing body of evidence suggests that obesity and eating disorders can co-exist in individuals and have shared risk factors, such as body dissatisfaction and dieting. ${ }^{8}$ Stigmatising comments from healthcare professionals can perpetuate the negative thoughts that a person has about their weight or body shape, which are known drivers of eating disorders. Furthermore, while eating disorders have high rates of morbidity and mortality, they may be more likely to be missed in patients who are overweight or who don't fit with societal preconceptions of what a person with an eating disorder should "look" like. ${ }^{9}$ As future healthcare professionals, we need to acknowledge the bias that exists in our medical curriculum.

\section{What can medical schools do?}

Highlight the multifactorial causes of obesity

Educating students on the multifactorial causes of obesity may help reduce stigma and "victim blaming." Obesity is not solely caused by patients being "lazy," "lacking in self-discipline," or being "noncompliant," as many stereotypes suggest. ${ }^{1}$ Environmental, genetic, lifestyle, and other unknown factors all interact to cause obesity. ${ }^{3} \mathrm{~A}$ key part of reducing obesity stigma in healthcare workers and medical students is educating them about these many factors and taking the "blame" for obesity off the patient's shoulders. A preliminary study in the US showed that an educational intervention focusing on the multifactorial causes of obesity, empathy induction, and roleplay improved the attitudes of medical students towards obese people. ${ }^{10}$

\section{Question the use of BMI}

Medical students should be taught to critically analyse the use of body mass index (BMI) as an indicator of health. Earlier this year, there was a call from members of Parliament to abandon the use of BMI, due to reports that it can worsen obesity stigma and damage people's physical and mental health and wellbeing. ${ }^{11}$ BMI has been called a "very poor proxy of health," which is not surprising given that it was created using studies of European males, making it less relevant for a diverse population. ${ }^{11}$ Medical students should instead be encouraged to look at other measures of health, such as waist circumference, blood pressure, and blood sugar.

\section{Health at Every Size (HAES)}

The Health at Every Size (HAES) approach has gained momentum in removing the focus from body weight, and instead encouraging a "fulfilling and meaningful lifestyle" through eating according to hunger and engaging in reasonable levels of physical activity. ${ }^{12}$ Its purpose is to reduce the social stigma and discrimination faced by overweight individuals and tackle chronic dieting behaviour, using a weight neutral approach that focuses on an individual's overall health and wellbeing, as opposed to the number on the scale. ${ }^{12}$ Weight loss diets have been found to have minimal success in the long run, which underlines the importance of exploring other methods of promoting health. ${ }^{13}$

\section{Address stigmatising behaviour}

Learning from and modelling the behaviour of senior doctors is an important part of medical education, which is sometimes called the hidden curriculum of 
medical school. Observing role models who demonstrate prejudice or discrimination towards obese individuals may perpetuate the cycle of stigma. In a study of healthcare students, $40 \%$ reported witnessing seniors make negative comments and jokes directed at obese patients..$^{14}$ Addressing stigmatising behaviour in a respectful way is important to break this cycle. A zero tolerance policy in healthcare settings towards discriminatory or derogatory behaviour may help achieve this goal. Furthermore, tackling weight stigma could help to focus consultations on the patient's needs, in instances where weight bias shifts the consultation away from this.

The stigma around obesity and its long term impact is seldom covered in medical school and is rarely included in the core curriculum. ${ }^{15}$ Discussing this stigma and strategies such as HAES as part of the curriculum via a lecture or a module could be a way to tackle doctors' stigma towards obese and overweight patients at the ground level.

Competing interests: none declared.

1 Puhl RM, Heuer CA. The stigma of obesity: a review and update. Obesity (Silver Spring) 2009;17:941-64. doi: 10.1038/oby.2008.636. pmid: 19165161

2 Puhl RM, Gold JA, Luedicke J, DePierre JA. The effect of physicians' body weight on patient attitudes: implications for physician selection, trust and adherence to medical advice. Int J Obes (Lond) 2013;37:1415-21. doi: 10.1038/ijo.2013.33. pmid: 23507996

3 Hruby A, Hu FB. The Epidemiology of Obesity: A Big Picture. Pharmacoeconomics2015;33:673-89. doi: 10.1007/s40273-014-0243-x. pmid: 25471927

4 Neumark-Sztainer D, Falkner N, Story M, Perry C, Hannan PJ, Mulert S. Weight-teasing among adolescents: correlations with weight status and disordered eating behaviors. Int I Obes Relat Metab Disord 2002;26:123-31. doi: 10.1038/sj.ijo.0801853. pmid: 11791157

5 Adams CH, Smith NJ, Wilbur DC, Grady KE. The relationship of obesity to the frequency of pelvic examinations: do physician and patient attitudes make a difference? Women Health1993;20:45-57. doi: 10.1300/J013v20n02_04. pmid: 8372479

6 Puhl RM, Brownell KD. Confronting and coping with weight stigma: an investigation of overweight and obese adults. Obesity (Silver Spring) 2006;14:1802-15. doi: 10.1038/oby.2006.208. pmid: 17062811

7 Amy NK, Aalborg A, Lyons P, Keranen L. Barriers to routine gynecological cancer screening for White and African-American obese women. Int J Obes (Lond) 2006;30:147-55. doi: 10.1038/sj.ijo.0803105. pmid: 16231037

8 Alberga AS, Russell-Mayhew S, von Ranson KM, McLaren L. Weight bias: a call to action. J Eat Disord 2016;4:34. doi: 10.1186/s40337-016-0112-4. pmid: 27826445

9 Arcelus J, Mitchell AJ, Wales J, Nielsen S. Mortality rates in patients with anorexia nervosa and other eating disorders. A meta-analysis of 36 studies. Arch Gen Psychiatry 2011;68:724-31. doi: 10.1001/archgenpsychiatry.2011.74. pmid: 21727255

10 Wiese HJ, Wilson JF, Jones RA, Neises M. Obesity stigma reduction in medical students. Int J Obes Relat Metab Disord 1992;16:859-68.pmid: 1337340

11 Mahase E. Stop using body mass index as measure of health, say MPs. BMJ2021;373:n941. doi: 10.1136/bmj.n941. pmid: 33836998

12 Penney TL, Kirk SF. The Health at Every Size paradigm and obesity: missing empirical evidence may help push the reframing obesity debate forward. Am J Public Health 2015;105:e38-42. doi: 10.2105/AJPH.2015.302552. pmid: 25790393

13 Hall KD, Kahan S. Maintenance of Lost Weight and Long-Term Management of Obesity. Med Clin North Am 2018;102:183-97. doi: 10.1016/j.mcna.2017.08.012. pmid: 29156185

14 Puhl RM, Luedicke J, Grilo CM. Obesity bias in training: attitudes, beliefs, and observations among advanced trainees in professional health disciplines. Obesity (Silver Spring) 2014;22:1008-15. doi: 10.1002/oby.20637. pmid: 24124078

15 Crowley J, Ball L, Hiddink GJ. Nutrition in medical education: a systematic review. Lancet Planet Health 2019;3:e379-89. doi: 10.1016/S2542-5196(19)30171-8. pmid: 31538623 